\title{
The UK Government LGBT Action Plan: Discourses of progress, enduring stasis, and LGBTQI+ lives 'getting better'
}

\section{Matson Lawrence and Yvette Taylor}

\begin{abstract}
The LGBT Action Plan (2018) represents a significant UK Government commitment towards LGBTQI+ equalities, operating in conjunction with cumulative legislative advances. Yet there is room for critique within this Plan, as proposed actions and as celebratory rhetoric of lives 'getting better'. Using empirical examples, this article examines how 'progress' for LGBTQI+ lives is discursively constructed and positioned in the LGBT Action Plan and accompanying politicians' speeches. We examine the key constructions of progress - across time, place, life courses, and normative thresholds - within which LGBTQI+ rights and realities are framed. We draw upon queer theory to illuminate discursive normativities and silences in representing 'policy problems' (Bacchi, 2009). While some policy areas are celebrated as signifiers of 'coming forward', others are relegated to the too tough in-tray, suspended in enduring stasis. Opposing 'political time' with 'queer time', this article concludes with the policy challenges posed by intersectional (in)equalities in these 'new times'.
\end{abstract}

Keywords: Gender; Inequality; Intersectionality; Lifecourse; Sexuality.

Funding: This research is part of the 'CILIA-LGBTQI+: Comparing Intersectional Lifecourse Inequalities amongst LGBTQI+ Citizens in Four European Countries' project (2018-2021), funded by NORFACE, a consortium of European research councils.

Conflict of Interest: No potential conflict of interest was reported by the authors.

\section{Dr Matson Lawrence and Professor Yvette Taylor, School of Education, University of Strathclyde}

Corresponding Author: Dr Matson Lawrence

Correspondence Address: School of Education, Level 5, Lord Hope Building, University of Strathclyde, 141 St James Road, Glasgow, G4 0LT. E-mail: matson.lawrence@strath.ac.uk 
AUTHOR COPY: The UK Government LGBT Action Plan: Discourses of progress, enduring stasis, and LGBTQI+ lives 'getting better'. Matson Lawrence and Yvette Taylor. 2019.

\section{Introduction}

In July 2018, the UK Government launched the LGBT Action Plan policy paper for 'improving the lives of lesbian, gay, bisexual and transgender people' (GEO, 2018a). Published by the Government Equalities Office (GEO) under the oversight of the then Minister for Women and Equalities, Penny Mordaunt MP, the Plan represents the first comprehensive cross-departmental policy paper specifically and solely addressing LGBTQI+ (in)equalities published by a UK Government (with the exception of the Transgender Action Plan (GEO, 2011) pertaining specifically to trans people). Making over 75 commitments across a range of key policy areas, the 29-page LGBT Action Plan 'explains how [Government] will advance the rights of LGBT people both at home and abroad' (GEO, 2018a).

The LGBT Action Plan draws upon findings from the National LGBT Survey, as the largest UK survey on the experiences of LGBTQI+ people, receiving 108,100 valid responses (GEO 2018b, 2018c). Statistics gathered via the National LGBT Survey and presented in the LGBT Action Plan demonstrate not only barriers, but high rates of incidents and criminalised acts motivated or aggravated by homo-, bi- and transphobias, alongside heightened incidence of direct and indirect discrimination across a range of life spheres including healthcare, employment, and education (GEO, 2018a, 2018b, 2018c). As Browne and Nash (2014: 327) assert, 'resistance to LGBT equalities is entrenched in Britain' and these resistances are 'developing and galvanizing', characterised by the mobilisation of right-wing and socially conservative groups in UK and international contexts, also capturing many interrelated issues of feminist concern (Phipps, 2019).

Nonetheless, we have witnessed significant change in legal rights for LGBTQ+ people, including same-gender marriage in England, Wales and Scotland, and comprehensive protection from discrimination instituted by the Equality Act 2010 (alongside broadly comparable antidiscrimination provisions in Northern Ireland). These legislative gains have been 'conceptualised as key moments of coming forward, whereby LGBT citizens have gained new public visibility and viable presence within a human rights framework' (Taylor, 2011: 335). Indeed, progress, as a comparative concept, discursively underpins the LGBT Action Plan and politicians' speeches delivered in tandem. Understood as an inevitable linear trajectory of 'moving forward' in space or 
time toward a more advanced position, progress is key to sociological and philosophical understandings and characterisations of modernity (Adkins, 2002; Mouzakitis, 2017).

However, amid what is articulated as unprecedented progress for LGBTQI+ rights and realities evidentially articulated through these legislative gains and the 'world we have won' (Weeks, 2007) - are manifestations of enduring stasis, where particular issues (and lives) are rendered immobile as perennial 'sticking points' and, in the words of Penny Mordaunt MP, as issues 'too tough' to address (GEO and Mordaunt, 2018). The extent to which the LGBT Action Plan represents shifts beyond policy status quo is questionable, with some areas - such as the experiences of LGBTQI+ people seeking asylum, LGBTQI+ rights post-Brexit, and pressing equality issues in devolved UK states - completely excluded, thus arguably reproducing existing absences, silences and enduring 'sticking points' in policy and politics.

As Ekins and King (2006: 222) observe, '[often], evidence of cultural transformation around sexual politics and identities forms a narrative of progressive change, but what is also found woven through the same works is an accompanying narrative of partial 'stasis', or 'lack of change'. Weeks (2007: 3) characterises these contemporary times as 'a world of transition, in the midst of a long, convoluted, messy, unfinished but profound revolution that has transformed the possibilities of living our sexual diversity and creating intimate lives'. The Plan was published at a time characterised by an at least decade-long period of fiscal austerity and cuts to public services and welfare (Farnsworth and Irving, 2018), and, more recently, the destabilising climate of 'Brexit'. It is within this non-linear messiness that we place our argument, and seek to unpack and problematize the discursive positioning of 'progress' in the LGBT Action Plan and related speeches.

\section{A note on terms}

We use the acronym 'LGBTQI+' when referring to lesbian, gay, bisexual, trans, queer and intersex identities, experiences, and ways of being; the '+' denotes related minoritised and marginalised sexual and gender identities, and sex characteristics. The acronyms used throughout this article vary in relation to the specific groupings discussed, for example we use 'LGBQ+' when referring 
to minoritised sexual and/or romantic identity only. Although useful referential acronyms for denoting sexual, gender and sex minorities, we acknowledge their usage as referential frames for identity are contested and potentially render invisible the systemic inequalities that (re)produce these classifications. As the acronym used in the policy paper, 'LGBT' is used when referring directly to or quoting from the LGBT Action Plan.

The term 'cis/cisgender' is utilised to differentiate from 'trans/transgender'; we use cis/cisgender to articulate subjectivities and systems that do not experience or recognise dissonances between gendered selfhood and embodied experience. Likewise, the term 'hetero' is utilised to differentiate from non-heterosexual (lesbian, gay, bisexual, queer) identity and experience. The terms 'cis' and 'hetero' operate to make explicit assumed neutral subject positions and systems, although we acknowledge these terms can be somewhat 'broad brush' and, when taken in isolation, do not necessarily fully articulate the complexities of gender and sexuality, both subjectively and systemically.

\section{Queering progress}

Queer and feminist researchers have long critiqued such linearity, framed in and assessed against heteronormative lifecourse milestones and thresholds, such as legally-enshrined rights to partnering and parenting. Key here is Halberstam's concept of 'queer time' and the 'strange temporalities' of queerness, where 'queer uses of time and space develop, at least in part, in opposition to the institutions of family, heterosexuality, and reproduction' (2005: 1). Policy orientations and the 'key victories' upon which political rhetoric on LGBTQI+ rights successes are fixed, however, follow cis-heteronormative time and trajectories - and the LGBT Action Plan and related political discourse is no exception.

Leading on from Halberstam (2005), Freeman (2010) uses 'chrononormativity', to refer to 'the interlocking temporal schemes necessary for genealogies of descent and for the mundane workings of everyday life' (xxiii). On an individual level, these 'temporal orders... produce assumed and expected heteronormative trajectories that may include ... ideas about the 'right' time for particular life stages' (Riach et al, 2014: 1678) such as living independently, marriage, having children, and 
retirement. On a broader level, these hetero-chrononormative imaginings underpin policy - upon the request of (some) LGBTQI+ people who want to get married and have children, for example, but also bolstered by subtextual presumptions that straight and / or cis lifecourses constitute the 'natural' or 'stable' order of a society, and the aspirational pinnacle of both human rights and relations (Wilson 2007). As Taylor (2017: 3.1) argues, '[neoliberal] capitalism shapes contemporary subjectivity where what is 'normal' is driven by a very particular and narrow mode of being, relating and valuing: driven by competition, inequality, and rational self-interest'. Such heteronormative lifecourse narratives are complicated further by gender - trans, non-binary, genderqueer - and the transgression or disruption of (cis) essentialist framings and trajectories (Pearce, 2018a).

\section{Constructing progress}

In this article, we examine four predominant identified constructions of progress - temporal, geopolitical, across the lifecourse, and across normative thresholds - in the LGBT Action Plan and speeches delivered by Penny Mordaunt MP and the then Prime Minister Theresa May at the time of its launch. In these sources, we examine how 'progress' for LGBTQI+ people is discursively constructed and positioned in policy and political terms; articulating the lives, rights and realities of people who identify (or are identified) as 'LGBTQI+' as inevitably and uniformly 'getting better'. The identified discursive constructions of progress are summarised below:

1. Normative thresholds: Progress across (cis-hetero-) normative thresholds, such as partnering and parenting as key 'life stages'.

2. Lifecourse: Progress across individual lifecourse trajectories, framed in neoliberal and meritocratic terms.

3. Temporal: Progress across time, comparing then and now.

4. Geo-political: Progress across place, comparing there and here.

These constructions of progress are conceptually employed in comparative dualistic frameworks of good and bad, better and worse; differentially positioning progress as 'better' now compared to then, 'better' here compared to there, contingently 'better' for the individual across their lifecourse, and 'better' because they can now do what we do. 
Following policy positioning and context, the next section outlines our methods and approach, with the successive four substantive sections examining the various constructions of getting better across these four constructions of progress: across normative thresholds, across the lifecourse, across time, and across place. Drawing upon the queer challenge to policy pragmatics, this article closes by querying whether intersectional inequalities related to LGBTQI+ lives can be articulated and actioned in policy terms.

\section{Positioning policy}

The substantive discussion and identified actions in the LGBT Action Plan are structured across nine sections, as follows: funding for the delivery of the plan, health, education, safety, workplace, rights and the law, data and monitoring, representation, and international. The Plan also includes three further accompanying sections - the Ministerial foreword by Penny Mordaunt MP, the executive summary, and 'next steps' for implementing the LGBT Action Plan commitments. The Plan's launch was accompanied by two key speeches on LGBTQI+ equalities delivered by senior Conservative Party politicians in July 2018: the official speech delivered at the LGBT Action Plan launch by Penny Mordaunt MP (GEO and Mordaunt, 2018); and the speech delivered by the then UK Prime Minister Theresa May at the 'Pride Reception' hosted in the gardens of 10 Downing Street (PMO and May, 2018).

The LGBT Action Plan is positioned as at once a policy and a strategy; although formally positioned by Government as a 'policy paper', the Plan reads more like a strategy outlining a range of commitments to 'take action' in selected governmental departments and locales, and on selected issues. The commitments contained therein are to be actioned by a range of governmental divisions, with varying applicability to the devolved states or nations comprising the UK (GEO, 2018a). Indeed, it is important to note that, while a national (i.e. UK) Action Plan in name, it 'will have varying levels of effect across the four nations of the UK' (GEO, 2018a: 5). While published by the UK Government, the LGBT Action Plan is mainly applicable to England and somewhat to Wales, with less purchase in Scotland and Northern Ireland due to existing devolution arrangements. The Plan sets out intentions to make available a $£ 4.5$ million LGBT Implementation 
AUTHOR COPY: The UK Government LGBT Action Plan: Discourses of progress, enduring stasis, and LGBTQI+ lives 'getting better'. Matson Lawrence and Yvette Taylor. 2019.

Fund 'to deliver commitments in this action plan and other projects' until the end of 2020 (GEO, 2018a: 7), available only to organisations in England.

\section{Methods and approach}

This article draws upon the UK Government's LGBT Action Plan policy paper and two key speeches delivered by politicians on the same day the LGBT Action Plan was published ( ${ }^{\text {rd }}$ July 2018). We began to examine the LGBT Action Plan on its launch date $-3^{\text {rd }}$ July 2018 - after reading press coverage and social media commentary on the Plan, the launch event, and the Pride Reception event hosted by the then Prime Minister. As the first comprehensive cross-departmental LGBTQI+-specific policy paper published by a UK Government, we thought it pertinent to examine the ways in which LGBTQI+ lives were represented and told in this watershed moment. This analysis was conducted as part of literature reviews and policy mapping work for the NORFACE-funded 'CILIA-LGBTQI+: Comparing Intersectional Life Course Inequalities amongst LGBTQI+ Citizens in Four European Countries' research (2018-2021).

First we collated a range of sources spanning the 14-month time period from the commencement of data collection for the National LGBT Survey (upon which the LGBT Action Plan is purportedly based) and until a few months following the LGBT Action Plan launch - i.e. between July 2017 and September 2018. These sources included the LGBT Action Plan policy paper (GEO, 2018a), the National LGBT Survey reports (GEO, 2018b, 2018c), key politician's speeches, survey findings and reports published by non-governmental organisations (NGOs), and UK mainstream media reporting on LGBTQI+ topics. The retrospective sourcing of news articles required use of internet archives (via LexisNexis). The survey reports and policy documents, including the LGBT Action Plan, are static documents and available online. Meanwhile, the politicians' speeches are indexed on and publicly available through the UK Government website. Collating and reading these sources provided a contextual backdrop upon which the key materials analysed in this article were identified. Indeed, the key sources - the LGBT Action Plan and the two related politicians' speeches - were identified for specific analysis because, when read together, they represent a specific moment in UK governmental policy and politics in relation to LGBTQI+ lives. 
The identified sources were read several times and manually coded thematically. The sources were then analysed utilising discourse analysis, informed by 'What's the problem represented to be?' framework approach to policy discourse analysis, incorporating poststructuralist and social constructionist theoretical approaches to examine the discursive framing, articulation and response to policy 'problems' (Bacchi, 2009). Such an approach to policy analysis 'challenges the commonplace view that policy is the government's best attempt to deal with 'problems", wherein 'governments are seen to be reacting to fixed and identifiable 'problems' that are exogenous [to] the policy process' (ibid: 1). Our approach centres discursive constructions as an inherent aspect of how these sources articulate and thus invoke us to think about LGBTQI+ issues, whilst analysing the exclusions, absences and 'discursive silences' (Morgan and Taylor, 2019; Sundaram and Saunston, 2016).

\section{'Better' across normative thresholds: (Re)inscribing essentialisms}

In their speeches delivered in tandem with the LGBT Action Plan launch, both Mordaunt and May outline what the Conservative government has 'done' for LGBTQI+ equalities since their election in 2010, citing the 'proud record' of their Government 'in advancing equality for LGBT people' (GEO 2018a: 1). Indeed, the way in which progress for LGBTQI+ equalities is conceived in the Plan is defined by a sense of 'political time', characterized here by 4-year governmental terms and short-term policy-making. There are not only fundamental incompatibilities between these temporal modalities and 'queer time' and liminalities, but also an awareness that 'political time' is temporally contingent and reactive, whilst being driven by party politics, populism and shifting social attitudes.

\section{The power of love}

As discussed previously with respect to queer temporalities and temporal discourses of progress, our analysis of the LGBT Action Plan and related sources identified discursive positioning of LGBTQI+ equalities as aligned to and measured against socio-culturally-specific cisheteronormative framings of 'key' life stages and normative thresholds, such as partnering and parenting. Penny Mordaunt's speech initially focuses on the centrality of 'love' as a driving and unifying principal of LGBTQI+ rights and equalities: 
'All that I have learnt is that everything is driven by love. What supports love, what promotes love is a good thing. And what hinders love, what fails to appreciate it, fails to recognise it for the heroic act it is, fails to understand how love fosters caring for one another and build strong and lasting relationships, well, that is an evil thing. Love deserves to be protected. It deserves to be celebrated. And it should never ever have to hide.'

Mordaunt articulates LGBTQI+ equalities - and particularly lesbian, gay, bi and queer people - as 'driven by love', tacitly positioning normative partnering as the way in which LGBTQI+ lives can be validated, accepted and made intelligible. This rhetoric is explicitly desexualized, and positions 'strong and lasting relationships' as those which are defining principles of acceptable LGBQ+ lives. Furthermore, Mordaunt's speech reifies same-gender and queer relationships as 'heroic' acts worthy of being 'celebrated'; serving to position non-heterosexual relationships as a brave choice that is external to default (heterosexual) subject positions. The discursive positioning of 'love' versus 'evil' facilitates a congratulatory subtext that positions heterosexual people who do not object to LGBTQI+ people's relationship formation as inherently 'good'.

The National LGBT Survey found that two-thirds of people avoid holding hands with a samegender partner in public due to fear of negative reactions (GEO, 2018b). While perhaps an unremarkable finding for LGBTQI+ people, both Mordaunt and May highlight this statistic specifically in their speeches: Mordaunt asserts that '[holding] hands with someone you love should be one of the simplest things in the world; not a source of fear or hesitation (GEO, 2018a: 1), while May states

That really struck me. Because, for heterosexual couples, holding hands is such a simple, normal gesture that we take it entirely for granted. That so many people fear the consequences of merely holding hands shows that a society in which we are all treated equally and fairly is still some way off. (PMO and May, 2018)

Here, May not only actively positions herself as heterosexual, but as the then Prime Minister and the most senior elected representative of the UK state, her use of 'we' can also infer the collective 
'we' or 'us' of a (heterosexual) nation and thus positioning LGBTQI+ as other to these conceptions of a collective or national identity. Furthermore, the use of the terms 'simple', 'normal' and 'merely' implicitly minimizes the gravity and significance of the act of holding hands in public as a visibly queer and/or trans person; that is, for many LGBTQI+ people, the act is in itself inherently politicized and decisions to do so are necessarily mediated by a range of contextual factors. Does this, therefore, really constitute and reflect the supposed progress for LGBTQI+ lives as posited by policy and politicians?

\section{Who, what and why 'LGBT'?}

While the 'LGBT' acronym is employed across a range of UK policy and NGO contexts, there is increasing usage of acronyms that are inclusive of 'intersex' and 'queer' (such as LGBTQ, LGBTI, and LGBTQI) and, as in this article, others have began to use ' + ' to denote a range of related marginalised or minoritised sexual and gender identities, lived experiences and ways of being. The inclusions and exclusions of letters in the acronym speak to broader enduring tensions, whether relating to an implied conflation of sexuality (LGB) and gender ( $T$ ), the underrepresentation of intersex (I) experience, or the contested re-appropriation of 'queer' (Q) both as an identity category and as resistance to such categorisation.

Marking a shift in policy framing, the LGBT Action Plan makes little reference to LGBT 'community' or 'communities' as is usual in policy contexts (Formby, 2017), instead referring to discrete categories of 'sexual orientation' and 'gender identity'. This resonates with and appeals to the individualised language of the Equality Act 2010 where matters related to sexuality and gender are positioned as personal 'characteristics', rather than as means of categorisation that are relationally constructed by socio-cultural contexts and conceptions.

Meanwhile, intersex embodiments mark a departing from the overarching linguistic framing of 'sexual orientation' and 'gender identity', with the absence of 'I' in the 'LGBT' acronym (re)producing implicit hierarchies of in/exclusions. Although the LGBT Action Plan is positioned as encapsulating those with variances in sex characteristics (i.e. intersex), only one action pertained specifically to intersex people. This action was a future commitment to gather evidence on the 
AUTHOR COPY: The UK Government LGBT Action Plan: Discourses of progress, enduring stasis, and LGBTQI+ lives 'getting better'. Matson Lawrence and Yvette Taylor. 2019.

barriers faced - despite a raft of evidence collected from 1,980 intersex survey respondents via the National LGBT Survey (GEO, 2018b), alongside the existing evidence published by scholars and scholar-activists (see Chase, 2013; Karkazis, 2008; Preves, 2003), and by Amnesty International (2017) and the United Nations (Méndez, 2013). Broadly speaking, the international consensus on the basics of intersex rights and autonomies has already been evidenced; in 2013, the United Nations Special Rapporteur on Torture called for nations globally to outlaw 'genital normalising' surgeries carried out on intersex individuals without their full informed consent (Al Hussein, 2015). As summarised by the social media campaign hashtag, '\#EndIntersexSurgeryNow'; that is, respect bodily autonomy and the right to self-determination, and specifically halt the practice of nonconsensual genital and gonadal surgeries and hormonal interventions on babies, children and young people. The commitment to gather more evidence therefore manifests the forstalling of equalities, with intersex rights suspended in enduring stasis. This static suspension is evident in other aspects of the LGBT Action Plan, such as the commitment to gather more evidence on the (already evidenced) barriers faced by non-binary and gender diverse people (see GEO, 2018a: 22).

Outwith policy discourse, there is huge variance in understandings and usage of sexual and gender identity terms, particularly among younger demographics (Paasonen and Spišák, 2018). Participants in the National LGBT Survey, upon which the LGBT Action Plan is purportedly based, were on average younger than the general UK population, with $69 \%$ of respondents aged 16-34, compared with just under a third (31\%) for the UK population as a whole (GEO 2018b: 9). According to GEO (2018b: 9), this is 'consistent with findings by the ONS that younger people are more likely to identify as LGB'; meanwhile other surveys have found that younger people are also more likely to view their sexuality and gender in fluid terms (Ditch the Label, 2017). The National LGBT Survey findings also suggested that younger respondents were more likely to identify their gender as non-binary than older respondents (GEO, 2018b). In terms of normative descriptions of 'LGBT' as an acronym and a collective descriptor, it is therefore pertinent to interrogate who and what is represented, and whether younger people in particular (dis)identify with the articulations and acronyms utilized in policy contexts. 


\section{'Better' across the lifecourse: Individualism and meritocracy}

In recent years, the notion of contingent progressive lifecourse trajectories for LGBTQI+ individuals is exemplified in the 'It Gets Better' campaign (hereafter IGB), a social media phenomenon started by gay activist Dan Savage in 2010 (Taylor, 2011). Instigated as a response to several highly-publicised suicides of LGBTQ+ teenagers in the United States, IGB consisted of online videos created by LGBTQI+ people and prominent non-LGBTQI+ 'allies' detailing how life 'gets better'. It has been argued that the IGB movement manifested heterogeneous representation of LGBTQI+ lives that advocates 'a host of queer worldmaking activities' (West et al, 2013: 49) which serves to 'queer sedimented logics that cast LGBTQ persons as without future' (Goltz, 2012: 135). Meanwhile, critiques of IGB have centred upon the class-based, aspirational neo-liberal acceptability politics discursively (re)presented in many video accounts (Taylor, 2011; Meyer, 2015).

These critiques of IGB are too applicable to discursive construction of progress or 'getting better' across the individual lifecourse in the LGBT Action Plan and related politicians' speeches. The LGBT Action Plan is positioned as 'improving the lives' of LGBTQI+ people - with both May and Mordaunt describing the National LGBT Survey findings as 'difficult', compelling 'more work to do' (GEO, 2018a: 1). However, understandings of structurally (re)produced inequalities and their differential impacts on progress for individual LGBTQI+ people's lives do not permeate the discourse. Instead, juxtaposed with statistical evidence of inequalities, progress across the individual LGBTQI+ lifecourse is positioned in meritocratic and neo-liberal framings, with this progress articulated in socio-economic terms and contingent upon individual action. As Mordaunt's introduction to the LGBT Action Plan states:

This Government is committed to making the UK a country that works for everyone... so that everyone can go as far as their hard work and talent can take them. The UK is a diverse and tolerant society. We have made great strides in recent decades to support [LGBT] people, who make a vital contribution to our culture and our economy. (GEO, 2018a: 1). 
AUTHOR COPY: The UK Government LGBT Action Plan: Discourses of progress, enduring stasis, and LGBTQI+ lives 'getting better'. Matson Lawrence and Yvette Taylor. 2019.

This asserts individualistic meritocratic concepts of moving forward, rooted in socially conservative and neoliberal values. The value of LGBTQI+ people is placed upon their actual or potential economic contribution. Moreover, this statement implicitly reproduces the two main stereotypical tropes often framed as the core contributions or value of LGBTQI+ people - that is, the Pink Pound ('our economy') and as artists and entertainers ('our culture').

\section{'Better' across time: From prejudice to proud allies}

2018 - the year the LGBT Action Plan was launched - marked 30 years since the introduction of Section 28/2A of the Local Government Act 1988, prohibiting the 'promotion of homosexuality' across local authority functions including (most notably) schools and public libraries. The vague wording of the legislation led to a climate of confusion and hesitation among schools teachers (Greenland and Nunney, 2008), often leading to self-censorship and educational cultures defined by their silences and absences. Section 28/2A was repealed in 2000 by the newly-empowered Scottish Parliament, and 2003 in England and Wales following a failed repeal attempt in 2000. Discussing Section 28/2A, Theresa May's speech is again articulated through the celebratory rhetorical framework of pride and progressive trajectories across time:

30 years ago, in a room that overlooks this garden, the government of the day took the decision to support the introduction of Section 28. It wasn't a complex piece of legislation - the core elements of the clause totalled fewer than 40 words. But, by silencing supportive voices and emboldening bigots, the devastation it wrought on a generation was immeasurable. It should never have been passed. My party - and I myself - should have voted to remove it from the statute book much sooner. I'm glad that it's now gone. And, today, I am proud to be an ally of lesbian, gay, bi and trans people everywhere. (PMO and May, 2018)

May's account tells the story of her own temporal journey towards acceptance and tolerance; from supporting anti-LGBTQI+ legislation in days past, to her proud allyship of today. May's selfassertion of being an 'ally' is evident too in Mordaunt's introduction to the LGBT Action Plan, where she states her position as a 'Stonewall LGBT Ally' (GEO, 2018a: 2); thus establishing her 'official' status, by holding a titled bestowed by a prominent LGBT charity. Moreover, May's 
AUTHOR COPY: The UK Government LGBT Action Plan: Discourses of progress, enduring stasis, and LGBTQI+ lives 'getting better'. Matson Lawrence and Yvette Taylor. 2019.

speech represents a displacement of 'bigots' to an unnamed elsewhere. Similarly, Mordaunt's speech stated:

Let us not forget that it was only 5 years ago that same-sex couples were allowed to marry, how prehistoric that already seems, let alone the bigotry that was so prevalent against gay men and women in the 1980s'. (GEO and Mordaunt, 2018).

This part of Mordaunt's speech posits a progressive present - and indeed future - against the backdrop of a parochial 'past'; in effect, positioning events of just five years previously as 'prehistoric', and further positioning homophobia in the 1980s as that which is beyond history, beyond emotional and corporeal memory, and beyond present lived realities.

New moments, past evocations: The 'too tough' area of trans equality

Against the discursive backdrop that reifies legislative and socio-political gains for LGBTQI+ rights, we turn here to Mordaunt's 'too tough' areas (GEO and Mordaunt, 2018) and focus specifically on issues aligned to trans equalities. In her speech, Penny Mordaunt highlights three specific areas 'which have perhaps for too long been in the too tough in-tray for our society' (GEO and Mordaunt, 2018). Mordaunt outlines these urgencies and tensions with respect to addressing LGBTQI+ bullying, and sex and relationships education (SRE) in primary and secondary schools; improving adult Gender Identity Clinics (GICs) and services in England; and, proposals to reform the Gender Recognition Act (GRA) 2004 to a self-declaration model, alongside legal recognition of a third gender category.

Expanding upon this, the LGBT Action Plan commits to five actions that pertain specifically to trans and non-binary people, including a pledge to 'ensure transgender people are treated with dignity and respect' in the legal gender recognition process (GEO, 2018a: 4); outlining a renewed commitment to publicly consult upon and review the GRA 2004. The GRA 2004 enables trans people to apply for a Gender Recognition Certificate (GRC); a GRC in turn enables trans people to obtain a new birth certificate reflecting their gender, and to update tax records accordingly. Meanwhile, the gender marker on many other forms of identification and records - such as UK 
AUTHOR COPY: The UK Government LGBT Action Plan: Discourses of progress, enduring stasis, and LGBTQI+ lives 'getting better'. Matson Lawrence and Yvette Taylor. 2019.

passports, driving licenses, and employment and health records - can be changed without a GRC (Lawrence and Mckendry, 2019). At present, the legally recognised gender categories in the UK are 'male' and 'female', while instituting a third gender category for non-binary and gender diverse people is subject to review as part of proposed reforms.

Myriad feminist theories of gender and sex, trans phenomenologies, and transfeminisms continue to usefully examine intersections and disjunctures for trans (in)equalities, all the while working under, within and against ill-fitting paternalistic and patriarchal state systems such as law and medicine (Hines, 2010; Pearce, 2018b). The LGBT Action Plans describes the legal gender recognition process under the GRA 2004 as 'bureaucratic and intrusive' (GEO, 2018a: 22), while the Scottish Government (2018) describes it as 'intrusive and onerous'. The process has been further characterized as paternalistic and pathologising (see Hines 2010): pathologising because a diagnosis of 'gender dysphoria' (a psychiatric disorder under the DSM-5) is required, alongside submission of medical reports detailing diagnoses, psychiatric assessments, and physical interventions (e.g. hormones, surgeries); paternalistic because applications are reviewed - and ultimately approved or rejected - by a Gender Recognition Panel, consisting of anonymous stateappointed legal and medical authorities.

Reforming the GRA 2004 was a manifesto pledge of most mainstream UK and Scottish political parties in the 2017 general election, and public consultations have since been conducted, yet draft legislation is still to emerge. Issues of trans equality and legal gender recognition have been characterised as key contemporary social justice issues (Hines, 2019), caught within deeply-felt schisms across feminism(s) and indeed wider society, bolstered by mainstream media attention and sensationalism. Debates centre on the nature and validity of (gendered) identities, trans experience, bodily autonomy, and legally-enshrined gender and sex categories and associated rights. Meanwhile, the voices of those with lived experience are often relegated to lacking critical insight into the systems and functions of gendered inequalities, and lacking 'genuine' autonomies to selfdeclare the (gendered) nature of their identity and embodied experience.

These ruptures have been evident, too, in the specific discourse surrounding and reactions to trans and gender diverse youth; for example, in 2018 alone, Mermaids (a charity for gender diverse youth 
and their families) was temporarily defunded by Big Lottery following coordinated campaigning against their work, while LGBT Youth Scotland was threatened with legal action over its affirmative guidance on supporting trans pupils in schools. Indeed, the issues surrounding both legal gender recognition and supporting trans youth are evocative of previous tensions and debates (Morgan and Taylor, 2019), such as those witnessed during Section 28/2A and subsequent campaigns to 'Keep The Clause' (Taylor, 2005a; 2005b), also now recirculating as in the case of significant protests against the LGBTQI+-affirmative 'No Outsiders' programme delivered in Birmingham schools. Calling into question linear conceptions of progress of inevitably and uniformly 'getting better', these tensions cyclically re-emerge to demonstrate the 'enduringly controversial nature of sexualities and gender intersectional issues' (Taylor, 2018: 1380).

The LGBT Action Plan pledges to examine 'the impacts on children and adolescents of changing their gender', making a specific commitment to 'gather evidence on the issues faced by people assigned female at birth who transition in adolescence' (GEO, 2018a: 9, emphasis ours). The Action Plan provides no evidence or rationale as to why those 'assigned female at birth', rather than all adolescents accessing gender-affirming clinical interventions, are the specific and sole policy focus here. This explicit yet unexplained focus on young people 'assigned female at birth' is therefore significant in policy terms, as is the broader focus on 'impacts' with implied negativity, because it denotes - and implicitly legitimises - contemporary contentious debates that position trans experience and gender diversity as a form of 'social contagion', particularly among youth assigned female at birth (see Serano, 2019). At this disjuncture, the differential discursive framing in the LGBT Action Plan between trans youth and cis LGBQ+ youth is particularly apparent; where homophobia and biphobia are framed as always unjustified and indefensible, through discursive silences and implicit biases there is a slipperiness of acceptability in the discourse pertaining to trans people - and trans youth in particular.

\section{'Better' across place: 'Global-leaders' in LGBTQI+ equalities}

The LGBT Action plan actively positions the UK as 'one of the best countries in Europe for LGBT rights' as recognised by ILGA-Europe (GEO, 2018a: 21) and a 'global leader' (GEO, 2018a: 27), discursively situating the UK as comparatively 'better' and as leader, arbiter and defender of LGBTQI+ rights continentally and internationally. While the ILGA-Europe country rankings for 
AUTHOR COPY: The UK Government LGBT Action Plan: Discourses of progress, enduring stasis, and LGBTQI+ lives 'getting better'. Matson Lawrence and Yvette Taylor. 2019.

legislation and policy affecting LGBTQI+ lives place the UK as $9^{\text {th }}$ out of 49 European countries, the LGBT Action Plan does not refer to its precise ranking nor the in-depth scoring; indeed, the UK legal standard of LGBTQI+ equality is assessed as only $61.78 \%$ compared to leading countries (ILGA-Europe, 2019). Meanwhile, the asserted position as 'global leader' is not directly evidenced in the LGBT Action Plan, however it does set out plans to allocate a range of funds to support LGBT rights 'internationally' and cites without context the UK's 'special responsibility' toward Commonwealth countries (GEO, 2018: 27-28).

Evocative of Puar's (2017) concept of homonationalism, the UK as a nation - and collection of nations - is discursively positioned in the LGBT Action Plan as comparatively 'progressive' and as supporting 'progress' elsewhere, while tacitly reinscribing (through both inclusion and omission) enduring tensions:

'While the UK is global leader on LGBT rights, we know there is more to do around the world to support LGBT people. We are heartened by the progress that many countries are making... We believe that LGBT people around the world deserve at least the same rights and respect that we enjoy in the UK and that the UK has a special responsibility to address laws discriminating against LGBT people in the Commonwealth. We will continue to defend and promote the rights of LGBT people globally.' (GEO, 2018a: 27)

In the above excerpt, the UK's positioning as 'global leader' is framed in paternalistic and neo/colonial terms. This is evident in the tacitly admonishing phraseology of being 'heartened by the progress' of 'many countries', and (by omission) making clear that 'some' countries are not deserving of such congratulation. This serves to implicitly embed a paternalistic arbitration of what constitutes 'progress' by positioning the 'rights and respect that we enjoy in the UK' as that which 'other' countries should aspire to, and by further positioning the UK as global arbiter of what constitutes the 'best' approach to furthering LGBTQI+ rights. The LGBT Action Plan states that the National LGBT Survey, upon which the LGBT Action Plan is based, 'did not ask any specific questions about international issues, but many respondents chose to talk about them in the open free-text response' (GEO, 2018a: 27); these contributions, however, are not extensively discussed in the survey report. There are further significant areas of absence with respect to the rights of 
asylum seekers and refugees, EU-citizens post-Brexit, and specific issues faced by Northern Irish residents.

These absences are acute in the context of mounting criticisms in relation to the treatment of people seeking asylum in the UK on the basis of actual or potential persecution related to marginalised sexualities, genders and sex characteristics. The UK asylum system has been characterised as deeply unjust for LGBTQI+ people, with numerous examples of individuals being compelled to tangibly 'prove' their sexuality or trans status, and the risks associated with this, or else face detention and deportation (Stonewall, 2010; Raboin, 2017). This serves to disrupt official narratives positioning the UK as 'one of the best places in the world to be LGBT', as these rights are arguably afforded only to those with the 'correct' documentation and insider (i.e. citizen) status. Marking a measured absence, the National LGBT Survey reportedly 'did not ask questions about the asylum process', however the Plan provides a loose commitment to 'continue our work to ensure that the needs of all LGBT claimants are met in the asylum process' (GEO, 2018a: 18).

\section{Devolution, difference and change}

Although based upon UK-wide data gathered via the National LGBT Survey and positioned as a UK policy paper, the LGBT Action Plan has uneven and limited applicability to Wales, Scotland and Northern Ireland due to existing devolution arrangements. Mordaunt's speech launching the Action Plan emphasised that she "will do everything in [her] power to ensure that our country, all four nations of it, is a place where everyone, whatever their gender identity or sexual orientation, can be themselves and live their lives with dignity and respect' (GEO and Mordaunt, 2018, emphasis ours). However, key areas identified in the Plan as major 'sticking points' in access and equality - such as health, education, and justice - are partially or wholly devolved matters, thus constituting them as outwith the remit of a UK-wide Action Plan and UK Government action to varying degrees. The material impacts of this are particularly pertinent in the context of ongoing struggles for equal marriage rights in Northern Ireland and access to gender-affirming healthcare in Wales, serving to re-inscribe differential access to equality based upon intra-UK locality. It is therefore pertinent to query an homogenizing policy and political discourse that positions the geo- 
politically differentiated locales comprising the UK as uniformly 'getting better' across spatial and legal boundaries, and to problematise dualistic distinctions of 'home and abroad'.

Relatedly, this period also saw mounting political and social tensions over 'Brexit', in preparation for the UK's withdrawal from the European Union re-scheduled for October 2019, with potential for destabilising consequences upon the legal rights of LGBTQI+ people in the UK. Current UK equalities legislation was prompted by EU legislation and treaties, including the Amsterdam Treaty (1997), the Charter of Fundamental Rights (2000), and various anti-discrimination directives (ILGA-Europe, n.d.). Consequently, legal scholars have analysed and questioned the foundational stability and futures of LGBTQI+ legal rights in a post-Brexit UK (Dunne, 2019). Despite these potentialities, the UK's withdrawal from the EU is not a topic discussed, addressed nor even footnoted in the LGBT Action Plan. The uncertainties surrounding and potentialities of Brexit serves to destabilise the notion of linear progressive temporal trajectories of 'getting better' or improvement as inevitability, and the geo-politically comparative notion of the UK as 'one of the best in Europe'.

\section{Conclusion}

In this article we have demonstrated the predominant constructions of 'progress' in the LGBT Action Plan policy paper and related sources, and have argued that these comparative discursive positionings reveal lasting tensions and enduring stasis in LGBTQI+ rights and differential lived realities. The LGBT Action Plan (GEO, 2018a) arguably represents a significant UK Government commitment towards LGBTQI+ equalities in practice, operating in conjunction with cumulative legislative shifts and advances. Progress, as a comparative concept, discursively underpins the LGBT Action Plan and related politicians' speeches delivered in tandem.

Yet, as we have demonstrated, there is room for scepticism and critique within such plans, as actions to be done and as celebratory rhetoric of progression and life 'getting better' for LGBTQI+ people - with the lives and rights of some suspended in enduring stasis. Planning progressively for LGBT equality often invokes temporal and spatial comparisons, between what, where, and ultimately who, is and is not acceptable, tolerable or equal. Despite the contradiction of UK legislation and planning, between prohibition of the 'promotion' of homosexuality (Section 28/2A) 
AUTHOR COPY: The UK Government LGBT Action Plan: Discourses of progress, enduring stasis, and LGBTQI+ lives 'getting better'. Matson Lawrence and Yvette Taylor. 2019.

and the LGBT Action Plan, these are glossed over in positioning the UK as a progressive nation, within which citizens can now uptake normative citizenship (Taylor, 2011). Positioning the UK as 'world leader' and 'one of the best countries in Europe for LGBT rights' discounts the multiplicities of sexual and gender identities and citizenship within and beyond the UK, where even the acronym (LGBT) may cause pause for thought in 'new times'. As such, the LGBT Action Plan represents a missed opportunity to cohesively address (in)equalities across key lifecourse spheres across and beyond the UK, and through its limited applicability serves to reinscribe differential access to equality on the basis of geo-political locality and citizenship status.

Returning to Mordaunt's discussion of the 'too tough' areas (GEO and Mordaunt, 2018), it is pertinent to consider the extent to which intersectional inequalities related (or not) to LGBTQI+ lives can be articulated and actioned in policy terms. Marginalities relating to, for example, age, gender, ethnicity, social class, disability, citizenship status and location serve to disrupt universalizing notions of 'LGBT equality' and a collective 'us' 'coming forward' (Taylor, 2007; Taylor et al., 2010). Indeed, intersectional inequalities compel policy challenges both within and beyond monolithic 'LGBT' categorisations, and highlight the ongoing discursive and material circulations of advancing equalities in policy and in practice (Munro and Richardson, 2010).

Queer theory's (Halberstam, 2005; Freeman, 2010) demonstration of 'queer time' as that which sits against cis-hetero-normative frames of recognition, pushes against rather than supports 'political time', challenging the 'problem' as progressively being taken care of by respective policy making. As queer and feminist researchers have variously highlighted, there are fundamental incompatibilities between 'queer time' and 'political time', as defined by short-term populist strategies. Through contrasting a queer perspective against a 'progressive' policy framework of the LGBT Action Plan, the discursive normativities and silences in representing the policy 'problem' (Bacchi, 2009) are illuminated; locating these in relation to time, place, normative thresholds, and recognised legitimated lifecourses. Queer (dis)engagement in policy making still arguably leaves the problem of what 'to do' in seeking LGBTQI+ equalities; concerned with the materiality and life of discourses, we utilised empirical examples from policy and political articulations to demonstrate how constructions of progress are employed in comparative dualistic frameworks. 
AUTHOR COPY: The UK Government LGBT Action Plan: Discourses of progress, enduring stasis, and LGBTQI+ lives 'getting better'. Matson Lawrence and Yvette Taylor. 2019.

Moreover, as the UK now careers towards exiting the European Union, the legislative basis for sexual and (trans)gender rights may be destabilized, with the lack of recognition of Brexit in the LGBT Action Plan casting further uncertainty as we enter these new times. These times also offer further pause for thought on whether progress and improvement is reserved specifically for LGBTQI+ insiders, and the potential fall-out for those rendered outsiders through enduring silences and omission. 
AUTHOR COPY: The UK Government LGBT Action Plan: Discourses of progress, enduring stasis, and LGBTQI+ lives 'getting better'. Matson Lawrence and Yvette Taylor. 2019.

\section{References}

Adkins L (2002) Revisions: Gender and Sexuality in Late Modernity. Buckingham: Open University Press.

Al Hussein ZR (2015) Opening remarks by Zeid Ra'ad Al Hussein, United Nations High Commissioner for Human Rights at the Expert meeting on ending human rights violations against intersex persons. Available at: https://www.ohchr.org/EN/NewsEvents/Pages/DisplayNews.aspx?NewsID=16431 (accessed 20 December 2018).

Amnesty International (2017) First, Do No Harm: Ensuring the Rights of Children Born Intersex. Available at: https://www.amnesty.org/en/latest/campaigns/2017/05/intersex-rights/ (accessed 20 December 2018).

Bacchi C (2009) Analysing Policy: What's the problem represented to be? Melbourne: Pearson Australia.

Browne K and Nash CJ (2014) Resisting LGBT Rights Where "We Have Won": Canada and Great Britain. Journal of Human Rights 13(3): 322-336.

Chase C (2013) Hermaphrodites with Attitude: Mapping the Emergence of Intersex Political Activism. In: Stryker S and Whittle S (eds) The Transgender Studies Reader. New York: Routledge, pp.300-314. DOI: 10.4324/9780203955055.

Ditch the Label (2017) The Valentine Study. Report, Ditch the Label, UK, February. Available at: https://www.ditchthelabel.org/research-papers/the-valentine-study/ (accessed 13 March 2019).

Dunne P (2019) Brexit: The Likely Impact on Sexual Orientation and Gender Identity Rights in the United Kingdom. In: Dustin M, Ferreira N and Millns S (eds) Gender and Queer Perspectives on Brexit. London: Palgrave Macmillan, pp.273-302. 
AUTHOR COPY: The UK Government LGBT Action Plan: Discourses of progress, enduring stasis, and LGBTQI+ lives 'getting better'. Matson Lawrence and Yvette Taylor. 2019.

Ekins R and King D (2006) The Transgender Phenomenon. London: Sage

Farnsworth K and Irving Z (2018) Austerity: Neoliberal dreams come true? Critical Social Policy 38(3): 461-481.

Formby E (2017) Exploring LGBT Spaces and Communities: Contrasting Identities, Belongings and Wellbeing. Abingdon, Oxon.: Routledge.

Freeman E (2010) Time binds: Queer temporalities, queer histories. Durham, NC: Duke University Press.

GEO (2018a) LGBT Action Plan: Improving the Lives of Lesbian, Gay, Bisexual and Transgender People. Policy paper, Government Equalities Office, UK, July. Available at:https://assets.publishing.service.gov.uk/government/uploads/system/uploads/attachment_data/f ile/721367/GEO-LGBT-Action-Plan.pdf (accessed 23 November 2018).

GEO (2018b) National LGBT Survey: Summary Report. Report, Government Equalities Office, UK, July. Available at: https://assets.publishing.service.gov.uk/government/uploads/system/uploads/attachment_data/file 1722314/GEO-LGBT-Survey-Report.pdf (accessed 29 November 2018).

GEO (2018c) National LGBT Survey: Research Report. Report, Government Equalities Office, UK, July. Available at:

https://assets.publishing.service.gov.uk/government/uploads/system/uploads/attachment_data/file 1721704/LGBT-survey-research-report.pdf (accessed 06 February 2019).

GEO (2011) Advancing Transgender Equality: A Plan for Action. Policy, Government Equalities Office, UK, December. Available from: https://www.gov.uk/government/publications/transgender-action-plan (accessed 12 March 2019). 
AUTHOR COPY: The UK Government LGBT Action Plan: Discourses of progress, enduring stasis, and LGBTQI+ lives 'getting better'. Matson Lawrence and Yvette Taylor. 2019.

GEO and Mordaunt P (2018) Launch Event: LGBT Action Plan 2018. Speech, Government Equalities Office, UK, July. Available at: https://www.gov.uk/government/speeches/launch-eventlgbt-action-plan-2018 (accessed 03 December 2018).

Goltz DB (2012) It Gets Better: Queer Futures, Critical Frustrations, and Radical Potentials. Critical Studies in Media Communication 30(2): 135-151.

Greenland K and Nunney R (2008) The repeal of Section 28: it ain't over 'til it's over. Pastoral Care in Education 26(4): 243-251.

Halberstam J (2005) In a Queer Time and Place: Transgender Bodies, Subcultural Lives. New York: NYU Press.

Hines S (2019) The feminist frontier: on trans and feminism. Journal of Gender Studies 28(2): 145157.

Hines S (2010) Recognising Diversity? The Gender Recognition Act and Transgender Citizenship. In: Hines S and Sanger T (eds) Transgender Identities: Towards a Social Analysis of Gender Diversity. New York: Routledge, pp.87-105.

ILGA-Europe (2019) Country Ranking. Available at: https://rainbow-europe.org/country-ranking (accessed 23 May 2019).

ILGA-Europe (n.d.) Five key facts on the EU and LGBT equality. Available at: https://www.ilgaeurope.org/sites/default/files/5_key_facts_on_the_eu_and_lgbt_equality__longer_version.pdf (accessed 11 February 2019).

Karzakis K (2008) Fixing Sex: Intersex, Medical Authority, and Lived Experience. Durham, NC: Duke University Press. 
AUTHOR COPY: The UK Government LGBT Action Plan: Discourses of progress, enduring stasis, and LGBTQI+ lives 'getting better'. Matson Lawrence and Yvette Taylor. 2019.

Lawrence M and Mckendry S (2019) Supporting Transgender and Non-Binary Students and Staff in Further and Higher Education: Practical Advice for Colleges and Universities. London: Jessica Kingsley Publishers.

Méndez JE (2013) Report of the Special Rapporteur on torture and other cruel, inhuman or degrading treatment or punishment. Report, United Nations Human Rights Council. Report, United Nations, Geneva, February. Available at: https://www.ohchr.org/Documents/HRBodies/HRCouncil/RegularSession/Session22/A.HRC.22. 53_English.pdf (accessed 20 December 2018).

Meyer D (2015) "One Day I'm Going to be Really Successful”: The Social Class Politics of Videos Made for the "It Gets Better" Anti-Gay Bullying Project. Critical Sociology 43(1): 113-127.

Morgan E and Taylor Y (2019) Dangerous Education: The Occupational Hazards of Teaching Transgender. Sociology 53(1): 19-35.

Mouzakitis A (2017) Modernity and the Idea of Progress. Frontiers in Sociology 7. DOI: 10.3389/fsoc.2017.00003.

Paasonen S and Spišák S (2018) Malleable identities, leaky taxonomies: The matter of sexual flexibility. Sexualities 21(8): 1374-1378.

Pearce R (2018a) Trans Temporalities and Non-Linear Ageing. In: King A, Almack K, Yiu-Tung S and Westwood S (eds) Older Lesbian, Gay, Bisexual and Trans People: Minding the Knowledge Gaps. Abingdon, Oxon: Routledge, pp.61-74.

Pearce R (2018b) Understanding Trans Health: Discourse, Power and Possibility. Bristol: Policy Press.

Preves S (2003) Intersex and Identity: The Contested Self. New Brunswick: Rutgers University Press. 
AUTHOR COPY: The UK Government LGBT Action Plan: Discourses of progress, enduring stasis, and LGBTQI+ lives 'getting better'. Matson Lawrence and Yvette Taylor. 2019.

Phipps A (2019) The fight against sexual violence. Soundings: A Journal of Politics and Culture 71: 62-74.

PMO and May T (2018) PM's speech at the Pride reception: 3 July 2018. Speech, Prime Minister's Office, UK, July. Available at: https:/www.gov.uk/government/speeches/pms-speech-at-thepride-reception-3-july-2018 (accessed 03 December 2018).

Puar JK (2017) Terrorist Assemblages: Homonationalism in Queer Times, 10 ${ }^{\text {th }}$ Anniversary Edition. Durham, NC: Duke University Press.

Raboin T (2017) Exhortations of happiness: Liberalism and nationalism in the discourses on LGBTI asylum rights in the UK. Sexualities 20(5-6): 663-681.

Riach K, Rumens N and Tyler M (2014) Un/doing Chrononormativity: Negotiating Ageing, Gender and Sexuality in Organizational Life. Organization Studies 35(11): 1677-1698.

Scottish Government (2018) Review of the Gender Recognition Act 2004: consultation analysis.

Report, Scottish Government, Scotland, November. Available at: https://www.gov.scot/publications/review-gender-recognition-act-2004-analysis-responsespublic-consultation-exercise-report/pages/3/ (accessed 24 May 2019).

Serano J (2019) Origins of "Social Contagion" and "Rapid Onset Gender Dysphoria". In: Julia Serano's Blog. Available at: http://juliaserano.blogspot.com/2019/02/origins-of-social-contagionand-rapid.html (accessed 24 May 2019).

Stonewall (2010) No Going Back: Lesbian and Gay People and The Asylum System. Report, Stonewall, UK, November. Available at: https://www.stonewall.org.uk/system/files/No_Going_Back_2010_.pdf (accessed 15 February 2019). 
AUTHOR COPY: The UK Government LGBT Action Plan: Discourses of progress, enduring stasis, and LGBTQI+ lives 'getting better'. Matson Lawrence and Yvette Taylor. 2019.

Sundaram V and Sauntson H (2016) Discursive silences: using critical linguistic and qualitative analysis to explore the continued absence of pleasure in sex and relationships education in England. Sex Education 16(3): 240-254.

Taylor Y (2018) Getting on? Doing sexuality then and now. Sexualities 21(8): 1379-1382.

Taylor Y (2017) Mediating 'Aspirant' Religious-Sexual Futures: In God's Hands? Sociological Research Online 22(1): 13. DOI: 10.5153/sro.4153.

Taylor Y (2011) Queer presences and absences: Citizenship, community, diversity - or death. Feminist Theory 12(3): 335-341.

Taylor Y (2007) Working-class lesbian life: Classed Outsiders. London: Palgrave Macmillan.

Taylor Y (2005a) Real Politik or Real Politics? Working-class lesbians' political 'awareness' and activism. Women's Studies International Forum 28(6): 484-494

Taylor Y (2005b) Inclusion, Exclusion, Exclusive? Sexual Citizenship and the Repeal of Section 28/2a. Sexualities 8(3): 375-380

Taylor Y, Hines S and Casey M (2010) Introduction. In: Taylor Y, Hines S and Casey M (eds) Theorizing Intersectionality and Sexuality. London: Palgrave Macmillan, pp.1-12.

Weeks J (2007) The World We Have Won: The Remaking of Erotic and Intimate Life. Oxon: Routledge.

West I, Frischherz M, Panther A and Brophy R (2013) Queer Worldmaking in the "It Gets Better" Campaign. QED: A Journal in GLBTQ Worldmaking 2013: 49-85.

Wilson AR (2007) With friends like these: The liberalization of queer family policy. Critical Social Policy 27(1): 50-76. 
AUTHOR COPY: The UK Government LGBT Action Plan: Discourses of progress, enduring stasis, and LGBTQI+ lives 'getting better'. Matson Lawrence and Yvette Taylor. 2019. 
AUTHOR COPY: The UK Government LGBT Action Plan: Discourses of progress, enduring stasis, and LGBTQI+ lives 'getting better'. Matson Lawrence and Yvette Taylor. 2019.

Author 1: Dr Matson Lawrence, School of Education, University of Strathclyde.

Correspondence Address: School of Education, Level 5, Lord Hope Building, University of Strathclyde, 141 St James Road, Glasgow, G4 0LT. E-mail: matson.lawrence@ strath.ac.uk

Biography: Matson Lawrence is a Research Associate based in the School of Education, University of Strathclyde. Together with Professor Yvette Taylor, he is currently working on the NORFACE-funded project 'Comparing Intersectional Lifecourse Inequalities among LGBTQI+ Citizens in Four European countries' (CILIA-LGBTQI+, 2018-2021). Matson previously worked on the award-winning TransEDU research project (2016-2018), culminating in his co-authored book Supporting Transgender and Non-Binary Students and Staff in Further and Higher Education (2019). Matson has been seconded to the Scottish Funding Council as a Senior Policy Analysis Officer, overseeing the Gender Action Plan for colleges and universities (2018). Matson led Creative Scotland-funded research on young disabled and D/deaf people's access to arts provision (2015-16), and has worked extensively with diverse LGBTQI+ communities in the third and arts sectors. He holds an interdisciplinary Doctorate from Durham University, where he was also a research assistant for several gender-based violence projects. Matson is based in Scotland.

Twitter: @MatsonLawrence

ORCID: https://orcid.org/0000-0001-9715-4898

Author 2: Professor Yvette Taylor, School of Education University of Strathclyde.

Biography: Yvette Taylor is Professor of Education and Deputy Head, School of Education, University of Strathclyde and Principal Investigator on the NORFACE-funded research project 'Comparing Intersectional Lifecourse Inequalities among LGBTQI+ Citizens in Four European Countries' (CILIA-LGBTQI+, 2018-2021). Further funded research projects include 'From the Coal Face to the Car Park? Gender and Class in the North East of England' (2007-09), 'Making Space for Queer-Identifying Religious Youth' (2011-13), 'Critical Terrain: Dividing Lines and Lives' (2013-14). Yvette has published four sole-authored books - Working-Class Lesbian Life: Classed Outsiders (2007), Lesbian and Gay Parenting: Securing Social and Educational Capital (2009), Fitting Into Place? Class and Gender Geographies and Temporalities (2012), and Making 
AUTHOR COPY: The UK Government LGBT Action Plan: Discourses of progress, enduring stasis, and LGBTQI+ lives 'getting better'. Matson Lawrence and Yvette Taylor. 2019.

Space for Queer Identifying Religious Youth (2016) - and she edits the Palgrave Macmillan Gender and Education Series. Yvette is based in Scotland.

Twitter: @YvetteTaylor0

ORCID: http://orcid.org/0000-0002-9260-5597 